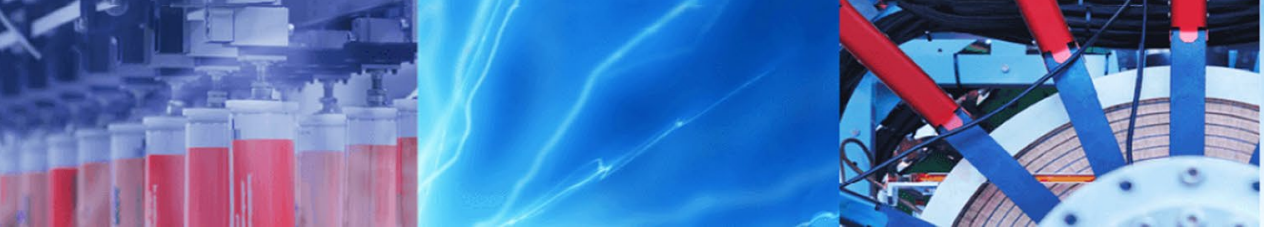

Research Article

\title{
A CFD study on hydrocarbon mean residence time in a horizontal oil-water separator
}

\author{
Tathagata Acharya $^{1}$ (D) Terry Potter $^{1}$
}

Received: 31 July 2020 / Accepted: 9 March 2021 / Published online: 23 March 2021

(c) The Author(s) 2021 OPEN

\begin{abstract}
This study presents computational fluid dynamics analyses on oil-water flow characteristics in a horizontal separator. The performance of these vessels are inferred from mean residence time and cumulative residence time distribution of the hydrocarbon phase inside the separator. The authors model a separator used by previous researchers and evaluate mean residence time of the hydrocarbon phase in a two-phase mixture of oil and water. Three different water-cuts of $21 \%, 32 \%$, and $57 \%$ are used. Additional analyses are done to assess how certain geometric features of the separator influence hydrocarbon mean residence time. The results show that the addition of a second perforated baffle plate does not improve the hydrocarbon mean residence time significantly. However, introducing a downward slanting throat section between the primary zone and the gravity separation zone improves the hydrocarbon mean residence time at $21 \%$ and $32 \%$ water-cuts. The results suggest oil-water separators with a throat section may be more efficient than regular horizontal separators without the throat section at low water-cuts.
\end{abstract}

Keyword Computational fluid dynamics · Multiphase separator $\cdot$ Mean residence time $\cdot$ Residence time distribution

$\begin{array}{ll}\text { Abbreviations } \\ \text { CFD } & \text { Computational fluid dynamics } \\ \text { MRT } & \text { Mean residence time } \\ \text { RTD } & \text { Residence time distribution } \\ c & \text { Phase concentration } \\ \text { a } & \text { Phase volume fraction } \\ \rho & \text { Fluid density } \\ u & \text { Fluid velocity in the } x \text { direction } \\ v & \text { Fluid velocity in the } y \text { direction } \\ \mu & \text { Dynamic viscosity }\end{array}$

\section{Introduction}

Multiphase separators are among the first production equipment through which the well fluids flow. The petroleum industry incurs large expenses to transport produced well fluids onshore. Since phase separation is done before the transportation of hydrocarbons, it is extremely important to design multiphase separators such that they function efficiently. While two-phase separators are used to separate oil from water, three-phase separators can separate oil, water, and natural gas. Multiphase separators can be classified as vertical, horizontal, spherical, and cyclone separators on the basis of construction. Vertical separators are commonly used when produced fluids have high gasoil ratio (GOR) $[1,2]$. They may also be used at locations with limited space. Horizontal separators are preferred when produced fluids have large fractions of liquids. Although spherical separators are less expensive, they are less commonly used because of their limited liquid settling section and surge space [3].

Phase separation in a three-phase horizontal separator is accomplished as the fluids pass through the following zones:

Tathagata Acharya, tacharya@csub.edu | Department of Physics and Engineering, California State University, Bakersfield, Bakersfield, CA, USA. 
a. Primary zone: This zone may or may not have an inlet diverter. If an inlet diverter is present, then the abrupt changes in the flow velocity cause the largest liquid droplets to drop by gravity after impinging on the diverter.

b. Gravity separation zone: The fluids then pass through a perforated baffle plate and enter the gravity separation zone. The flow velocity is reduced, and the fine liquid droplets separate out from gas phase by gravity. This zone also has the liquid collection zones where the hydrocarbon and aqueous phases are collected.

c. Mist elimination zone: This zone has coalescing plates, vanes, and wire pad mesh. These provide impinging surface for very fine droplets such that they can coalesce and separate by gravity. Figure 1 shows a typical schematic of a three-phase horizontal separator.

Researchers over the years have studied flow characteristics in multiphase separators. Mean residence time (MRT) is an important figure of merit that is considered in the design of multiphase separators. It is defined as the amount of time a given phase stays within the separator. Many articles list different thumb rules for designing of multiphase separators [4-8]. Operators on field often measure MRT as the ratio of volume of the hydrocarbon phase to the phase volumetric flowrate. The oil-water interface is obtained using level-controllers. The volume occupied by each phase is obtained by assuming that the interface height can be extrapolated back from the weir to the separator inlet. Therefore, this method involves significant errors [9]. A more accurate method of calculating MRT is by using residence time distribution (RTD). RTD for a given phase is defined as the fraction of elements leaving the separator between times $t$ and $t+\Delta t$. It is given by Eq. (1):

$R T D=\frac{c(t)}{\int_{0}^{\infty} c(t) d t}$,

where $c(t)$ is the concentration of a given phase at the outlet as a function of time $t$. Therefore, over time the cumulative residence time distribution (CRTD) can reach a maximum value of 1. MRT can be calculated using Eq. (2):

$M R T=\frac{\int_{0}^{\infty} t c(t) d t}{\int_{0}^{\infty} c(t) d t}$

Although many articles exist on gas-liquid separation [10-15], available data on liquid-liquid separation is far from adequate. While the density ratio in gas-liquid systems is in the range of $0.001-0.1$, it is usually $0.7-1.1$ in liquid-liquid systems. Therefore, flow characteristics in liquid-liquid systems is harder to predict than gas-liquid systems. Few studies exist that use residence time distributions to evaluate mean residence time in oil-water horizontal separators [9, 16-20]. Besides, fewer articles detail the variation of MRT with changing water-cut (water volume fraction) and separator internal configuration [9, $16,17]$. Produced fluids contain mixtures of oil, gas, and water, and the water-cut varies over time. Therefore, it is very important to assess hydrocarbon MRT as a function of water-cut. Although reservoir fluids almost always produce natural gas as a biproduct, for oil-water separation studies the presence of natural gas may be ignored. The large density difference between natural gas and oil suggests that the oil-water separation results are not impacted by the presence of small amounts of natural gas in the mixture.

Simmons et al. performed experiments on a horizontal separator and measured mean residence time (MRT) and residence time distribution (RTD) by varying watercut in a mixture of kerosene and water [16]. A previous article published by the lead author reported computational fluid dynamics (CFD) simulation results where they calculated MRT for the hydrocarbon phase in a mixture of kerosene and water with varying water-cuts [17]. CFD can be effectively used to predict MRT and therefore can replace expensive experiments. To the best of our knowledge no article has reported the effect of increasing the number of baffle plates and introducing a throat section on hydrocarbon phase MRT with varying water-cuts. In the present manuscript, the authors extend the analyses
Fig. 1 Schematic of a threephase horizontal separator

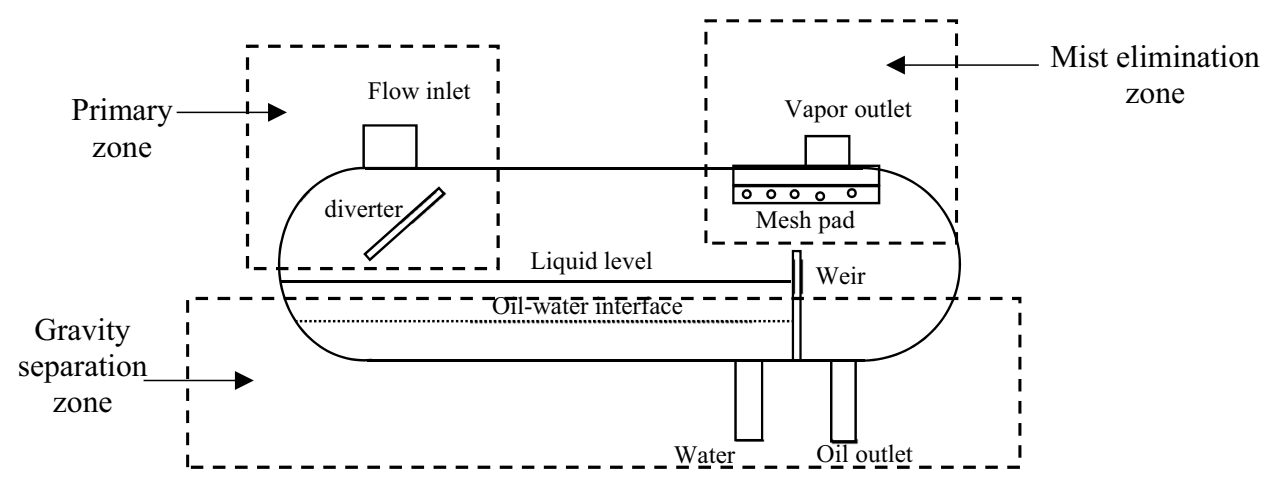


from the previous article by the lead author's group to include light crude-oil instead of kerosene. In addition, the authors study three different separator geometries and their influence on the hydrocarbon phase MRT with varying water-cuts.

\section{Materials and methods}

\subsection{Simulation geometries}

Simulations were performed using three different geometries: (a) a separator with a single perforated baffle plate and (b) a separator having two perforated baffle plates and (c) a gravity assisted separator. Figure 2 shows simulation geometry (a) with the single perforated baffle plate.

The separator geometry was chosen based on experimental work done by previous researchers [16]. Subsequent CFD analyses using the same geometry were recently reported in another article by the lead author [17]. The separator was $2.5 \mathrm{~m}$ in length and $0.6 \mathrm{~m}$ in diameter. The separator had a $0.02 \mathrm{~m}$ thick perforated baffle that separated the primary zone from the gravity separation zone. The baffle plate had a permeability of $2 \times 10^{-9} \mathrm{~m}^{2}$. The weir height in the separator was $0.3 \mathrm{~m}$. The diameter of the inlet and each outlet was $0.05 \mathrm{~m}$. The length of the gravity separation zone was $2.18 \mathrm{~m}$ with the weir placed halfway between the two outlets.

Figure 3 shows the second simulation geometry with two perforated baffle plates, each $0.02 \mathrm{~m}$ thick within the separator used in (a). The perforated baffle plates were $0.2 \mathrm{~m}$ apart.

Figure 4 shows simulation geometry (c): the gravity assisted separator. The inlet zone of this separator had a slanted entrance path leading up to the baffle plate. Although the dimensions of the separation zone downstream of the baffle plate were the same as geometries (a) and (b), a downward slanting throat section connected the primary zone with the gravity separation zone. The gravity assisted inlet zone was inspired by the work of previous

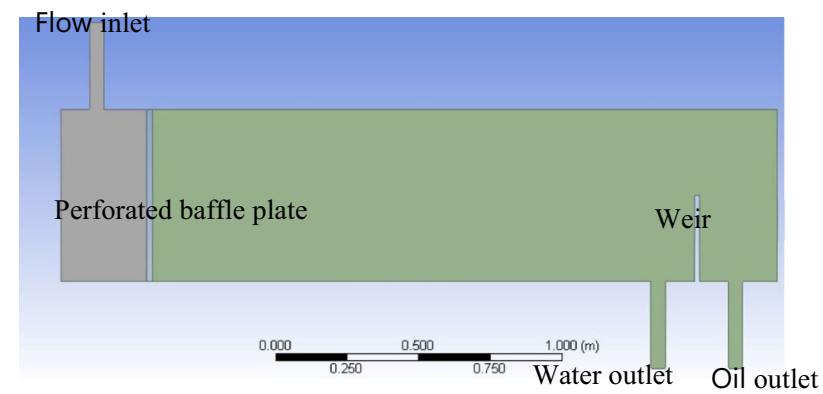

Fig. 2 Simulation geometry (a): separator with single baffle plate

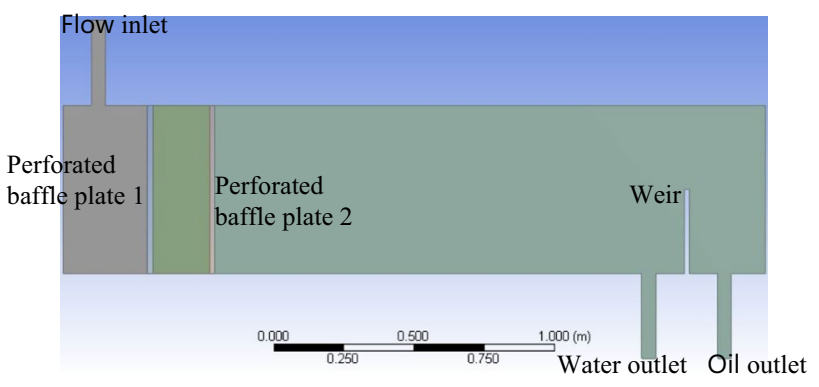

Fig. 3 Simulation geometry (b): separator with two baffle plates

researchers [21]. Also, the inlet and outlet diameters and the weir height were the same as geometries (a) and (b).

\subsection{Numerical model}

Two-dimensional multiphase CFD simulations were performed using ANSYS Fluent 18.2 [22]. The authors in their previous article showed that the two-dimensional CFD model could correctly predict the trend of hydrocarbon mean residence times wth varying water-cuts in a horizontal separator. Besides, the computational costs associated with the two-dimensional CFD model are much lesser than the three-dimensional CFD model. The CFD code uses finite volume method to solve Navier Stokes equations in two dimensions. The Reynolds Number based on the inlet velocities ranged from $25,000-68,000$ suggesting turbulent flows in the primary zone. The standard k- $\varepsilon$ turbulence model was used because of the large velocities at the inlet. The $k-\varepsilon$ model is widely used for its relatively low computational cost. It is also popular because of its applicability to planar shear flows and recirculating flows. It is also used in similar multiphase flow applications [15, 18,23 ]. The liquid-liquid dispersions in horizontal gravity separators are dense and the volume fractions vary from

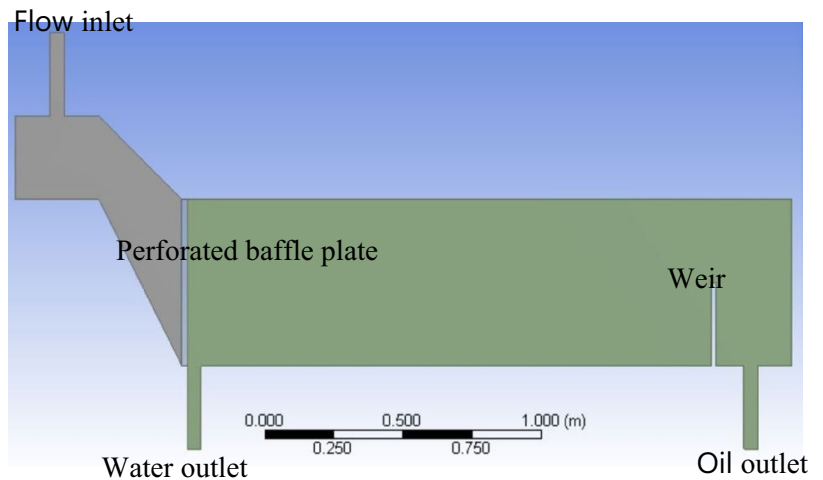

Fig. 4 Simulation geometry (c): gravity assisted separator with one baffle plate 
0 to $100 \%$. Therefore, for the two-phase mixture of water and light crude oil, the Eulerian multiphase model was used where the phases were treated as interpenetrating continua and a separate set of continuity and momentum equations were solved for each phase $[24,25]$. Using this model, a single pressure is shared by all phases. The continuity and momentum equations are used for all phases as shown by Eqs. (3), (4), and (5):

$\frac{\partial}{\partial t}(\alpha \rho)+\frac{\partial}{\partial x}(\alpha \rho u)+\frac{\partial}{\partial y}(\alpha \rho v)=0$,

$\frac{\partial}{\partial t}(\alpha \rho u)+u \frac{\partial}{\partial x}(\alpha \rho u)+v \frac{\partial}{\partial y}(\alpha \rho u)=-\alpha \frac{\partial P}{\partial x}+\alpha \rho g_{x}+\frac{\partial}{\partial x}\left(\alpha \mu \frac{\partial u}{\partial x}\right)+\frac{\partial}{\partial y}\left(\alpha \mu \frac{\partial u}{\partial y}\right)$,

$\frac{\partial}{\partial t}(\alpha \rho v)+u \frac{\partial}{\partial x}(\alpha \rho v)+v \frac{\partial}{\partial y}(\alpha \rho v)=-\alpha \frac{\partial P}{\partial y}+\alpha \rho g_{y}+\frac{\partial}{\partial x}\left(\alpha \mu \frac{\partial v}{\partial x}\right)+\frac{\partial}{\partial y}\left(\alpha \mu \frac{\partial v}{\partial y}\right)$,

where $\rho$ is the density of the fluid, $u$ and $v$ are the velocities in the $x$ and $y$ directions respectively, $\mu$ is the dynamic viscosity of the fluid, $g$ is the acceleration due to gravity, and $\alpha$ is the volume fraction of a given phase such that:

$\alpha+\beta=1$,

where $\beta$ is the volume fraction of the other phase. The energy equation was not solved as no significant temperature changes were involved. Equations (7) and (8) show the transport equations for the $k-\varepsilon$ turbulence model:
Table 1 Properties of water and light crude-oil

\begin{tabular}{lll}
\hline Fluid & Water & Light crude-oil \\
\hline Density, kg/m3 & 998.2 & 827 \\
Dynamic viscosity, mPa-s & 1.003 & 5.905 \\
API gravity & 10 & 39.39 \\
\hline
\end{tabular}

inside the separator were set at 0 suggesting an empty separator at start. Three different water-cuts $(21 \%, 32 \%$, and $57 \%$ ) were used in a mixture of light crude oil and

$\frac{\partial}{\partial t}(\rho k)+\frac{\partial}{\partial x_{i}}\left(\rho k u_{i}\right)=\frac{\partial}{\partial x_{j}}\left[\left(\mu+\frac{\mu_{t}}{\operatorname{Pr}_{k}}\right) \frac{\partial k}{\partial x_{j}}\right]+G_{k}+G_{b}-\rho \varepsilon-Y_{M}+S_{k}$

$\frac{\partial}{\partial t}(\rho \varepsilon)+\frac{\partial}{\partial x_{i}}\left(\rho \varepsilon u_{i}\right)=\frac{\partial}{\partial x_{j}}\left[\left(\mu+\frac{\mu_{t}}{P r_{\varepsilon}}\right) \frac{\partial \varepsilon}{\partial x_{j}}\right]+C 1_{\varepsilon} \frac{\varepsilon}{k}\left(G_{k}+C 3_{\varepsilon} G_{b}\right)-C 2_{\varepsilon} \rho \frac{\varepsilon^{2}}{k}+S_{\varepsilon^{\prime}}$

where $G_{k}$ represents the generation of turbulence kinetic energy due to mean velocity gradients, $G_{b}$ is the generation of turbulence kinetic energy due to buoyancy, $Y_{M}$ is the contribution of the fluctuating dilation in compressible turbulence to the overall dissipation rate. $\mathrm{C1}_{\varepsilon^{\prime}} \mathrm{C2}_{\varepsilon^{\prime}}$ and $\mathrm{Cl}_{\varepsilon}$ are constants, and $\mathrm{Pr}_{k}$ and $\mathrm{Pr}_{\varepsilon}$ are turbulent Prandtl numbers for $k$ and $\varepsilon . S_{k}$ and $S_{\varepsilon}$ are user defined source terms. The Phase-Coupled Simple Algorithm was used for pressure-velocity coupling. For the spatial discretization, second order upwind was used for momentum, turbulent kinetic energy and turbulent dissipation rate. Velocity boundary condition was set at the flow inlet while pressure boundary condition was set at the outlets. As the initial condition, the volume fractions of both oil and water water.

The densities and the dynamic viscosities of the two liquids are shown in Table 1. The mass-flowrate of water was kept fixed at $4 \mathrm{~kg} / \mathrm{s}$.

The simulation geometry (a) was meshed with quad mesh elements with the maximum face size being $0.0025 \mathrm{~m}$. Mesh independence was obtained with 240,552 mesh elements. The oil velocity at the oil outlet was used for the mesh independence test. Figure 5 shows the result from mesh independence study.

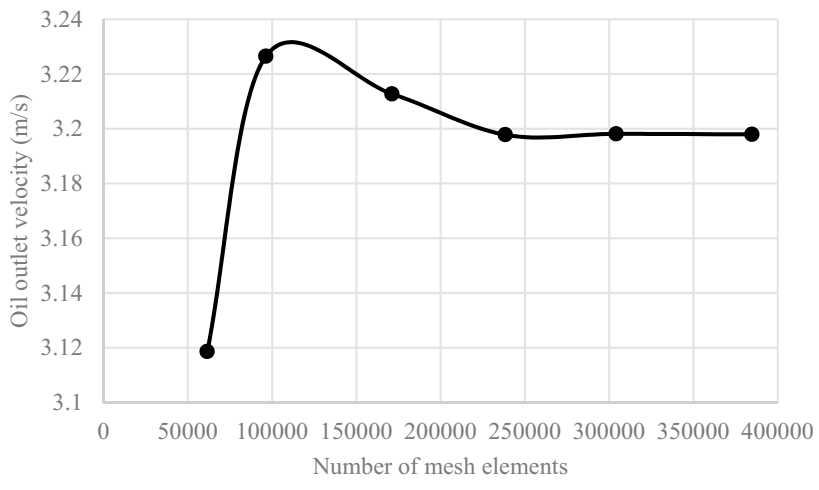

Fig. 5 Mesh independence study showing results not changing appreciably when number of mesh elements exceed 240,552 


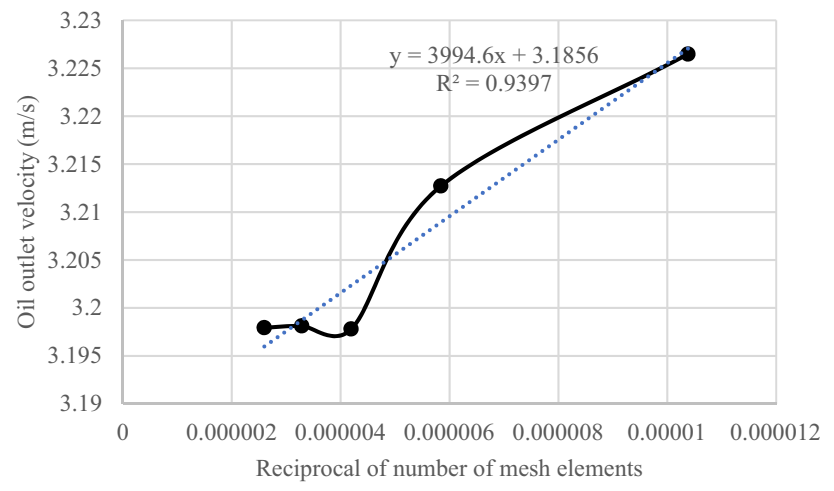

Fig. 6 Limiting results showing the result when number of mesh elements tend to infinity

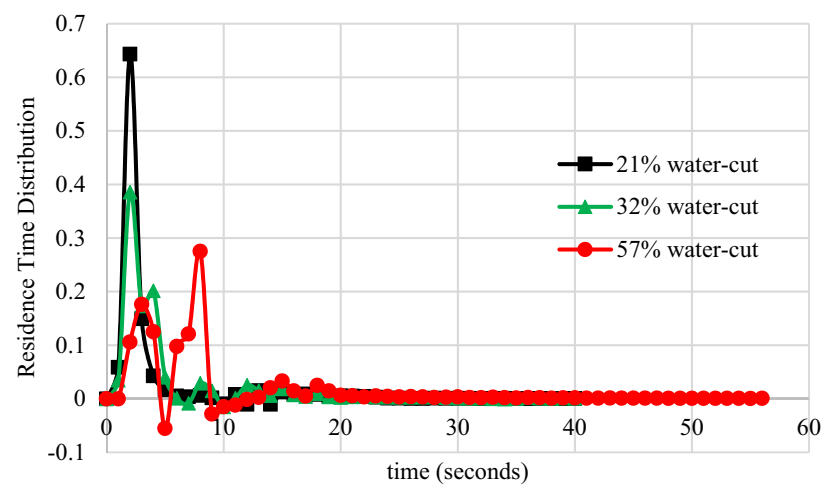

Fig. 7 Geometry (a)-Residence time distribution at different water-cuts

Figure 6 shows the limiting results if the number of mesh elements tend to infinity. From Fig. 5, the data point at the lowest number of mesh elements is removed and oil outlet velocity is plotted against the reciprocal of the number of mesh elements. A linear curve fit is used and the equation for the line is $y=3994.6 x+3.1856$. For the limiting case, as the number of mesh elements tend to infinity, $x$ tends to zero. Therefore, the limiting value of oil velocity at oil outlet is $3.1856 \mathrm{~m} / \mathrm{s}$. The goodness of the fit is 0.9397 .

\section{Model validation}

Geometry (a) used by the authors has the same dimensions as the one used by Simmons et al. [16]. Figure 7 shows a comparison of residence time distributions (RTD) with geometry (a) at the three water-cuts.

The results obtained using geometry (a) are qualitatively validated against the experimental results obtained by Simmons et al. and are shown in Table 2 .

In the previous article published by the lead author, a horizontal liquid-liquid separator was studied and the mean residence time (MRT) of the hydrocarbon phase was calculated at varying water-cuts in a mixture of kerosene and water [17]. In this article, the authors assess the performances of three different separator geometries by studying the hydrocarbon phase MRT and cumulative residence time distribution (CRTD).

\section{Results and discussion}

\subsection{Separator geometry (a)}

Geometry (a) is the same as the configuration used by the authors in their previous article [17]. However, as mentioned in the previous section, the hydrocarbon phase is light crude oil. Figures 8, 9, and 10 show the flow characteristics within geometry (a) at start (empty separator), at time $t=5 \mathrm{~s}$ and at time $\mathrm{t}=20 \mathrm{~s}$, at a water-cut of $21 \%$.

Geometry(a) is simulated with three different watercuts of $21 \%, 32 \%$, and $57 \%$. At each water-cut, MRT is calculated when CRTD approaches 1. Figure 11 shows CRTD curves at each water-cut with geometry (a). The CRTD curve at $21 \%$ water-cut approaches 1 faster than the other water-cuts. At 57\% water-cut, the CRTD curve is the slowest to approach 1.

This suggests that, MRT increases with increase in water-cut in geometry (a). Figure 12 shows the effect of water-cut on MRT in separator geometry (a).

These results agree with the experimental data obtained by previous researchers [16] and with similar computational work by the lead author's research group [17].
Table 2 Comparison of CFD results against experiments

\begin{tabular}{ll}
\hline Serial No & CFD results agreeing with experiments \\
\hline 1 & Crude-oil MRT increases with increase in water-cut \\
2 & With the single baffle plate configuration, RTD peaks occur close to start \\
3 & RTD peak height drops with increase in water-cut \\
4 & RTD peaks shift towards the right on the plot with increase in water-cut \\
5 & At larger water-cuts secondary RTD peaks are observed \\
\hline
\end{tabular}




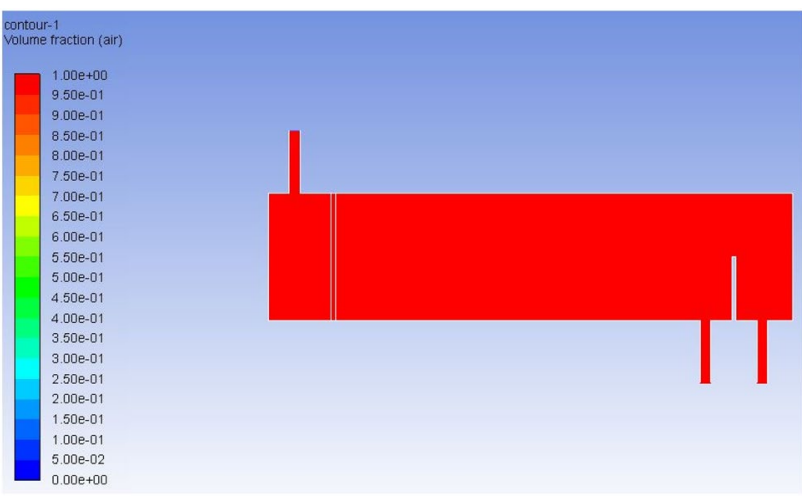

Fig. 8 Geometry (a): At time $t=0$, the separator is empty and the volume fraction of air is 1

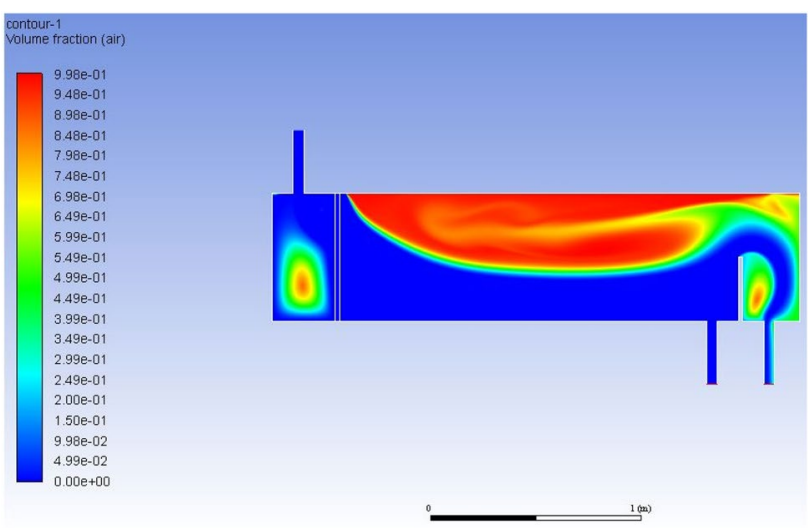

Fig. 9 Geometry (a): At time $t=5 \mathrm{~s}$, the oil-water mixture partially fills the separator and flows over the weir

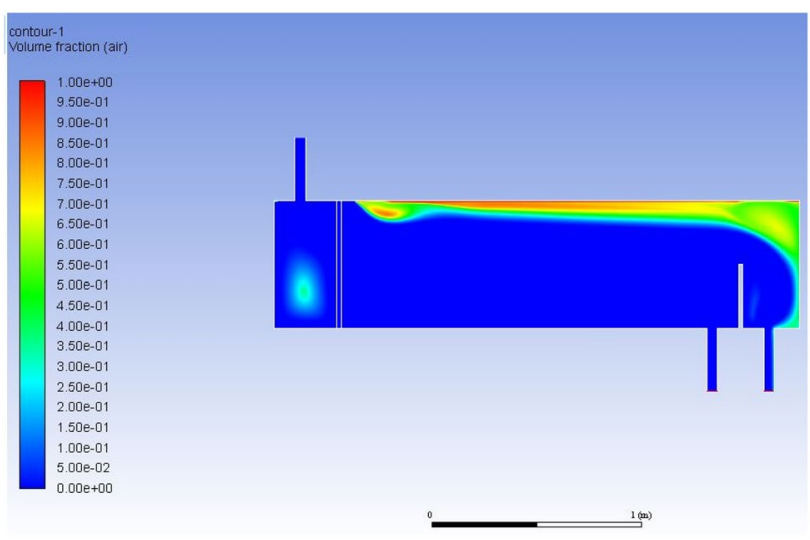

Fig. 10 Geometry (a): At time $t=20 \mathrm{~s}$, the oil-water mixture substantially fills the separator

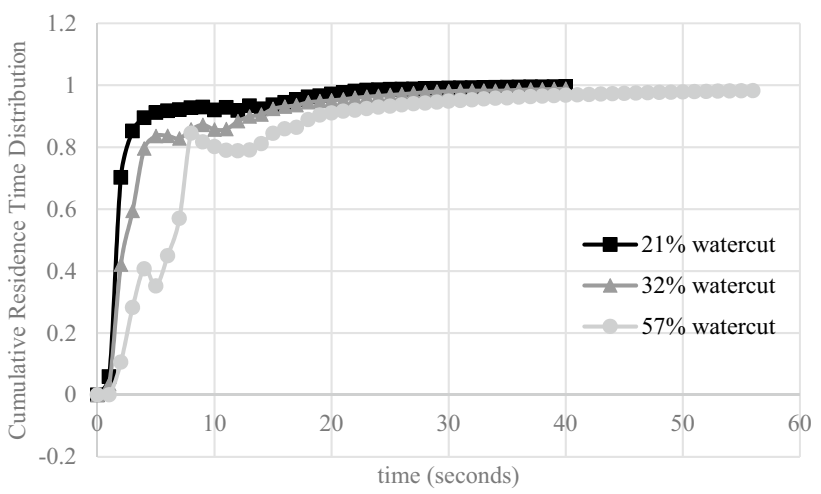

Fig. 11 Geometry (a): Cumulative Residence Time Distribution at different water-cuts

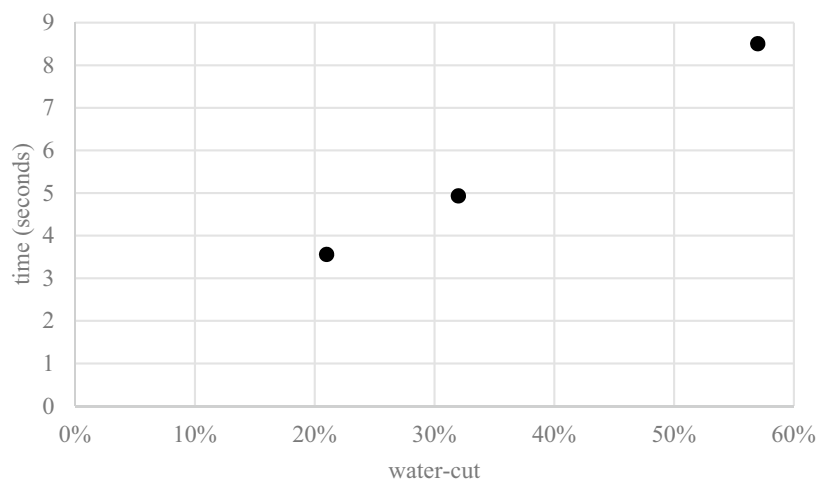

Fig. 12 Geometry (a): Effect of water-cut on hydrocarbon mean residence time (MRT)

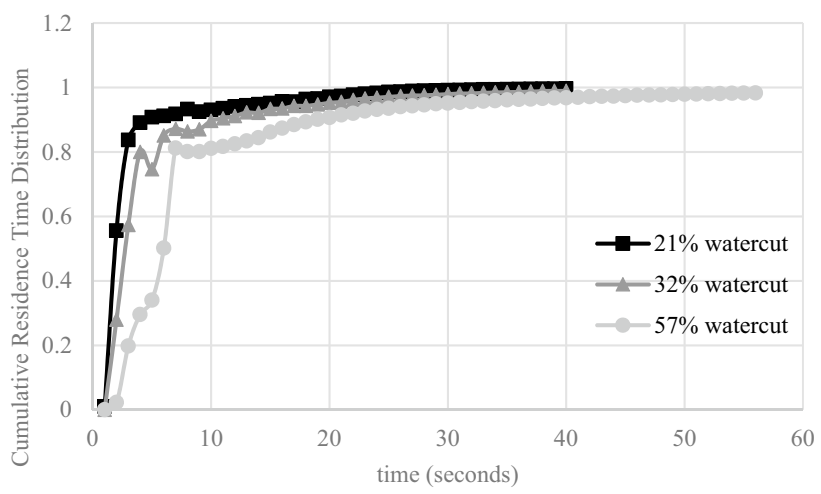

Fig. 13 Geometry (b): Cumulative Residence Time Distribution at different water-cuts 


\subsection{Separator geometry (b)}

Separator geometry (b) has the same dimensions as geometry (a) with the exception of a second baffle plate. Figure 13 shows the CRTD curves at the same water-cuts with geometry (b). Similar to geometry (a), the CRTD curve at $21 \%$ water-cut is the quickest to approach 1 . Also, the CRTD curve at $57 \%$ water-cut is the slowest to approach 1 suggesting the largest MRT at the highest water-cut.

Figure 14 confirms that MRT increases with increase in water-cut in geometry (b).

MRTs at $21 \%$ and $32 \%$ water-cuts are slightly larger in geometry (b) than geometry (a). However the MRT at 57\% water-cut is slightly larger in geometry (a) than geometry (b). This suggests that adding a second baffle plate does not improve the separator performance significantly. Figure 15 shows the oil velocity vectors across the first baffle

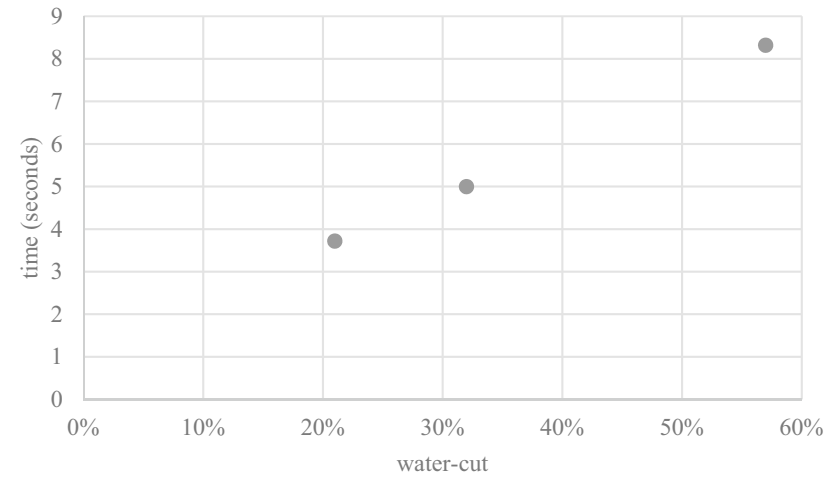

Fig. 14 Geometry (b): Effect of water-cut on hydrocarbon mean residence time (MRT) plate in geometry (b). Oil velocity reduces significantly across the first baffle plate.

However, the velocities do not drop any further as oil passes through the second baffle plate. Therefore, the oil velocities downstream of the second baffle plate in geometry (b) are not significantly different from the the oil velocities downstream of the first baffle plate in geometry (a). This suggests towards similar MRT values in both geometry (a) and geometry (b). Figure 16 shows oil velocity vectors as oil passes through the second baffle plate.

\subsection{Separator geometry (c)}

The gravity separation zone in separator geometry (c) has the same length as separator geometries (a) and (b). However, the primary zone includes the throat section that uses gravity to add momentum to the oil-water mixture flow. Figure 17 shows CRTD curves at the same watercuts of $21 \%, 32 \%$, and $57 \%$ with separator geometry (c). Contrary to geometries (a) and (b), the CRTD curve at $21 \%$ water-cut is the slowest to approach 1. The CRTD curve at $32 \%$ water-cut is the quickest to approach 1 . At $21 \%$ watercut the CRTD curve drops from 0.8 to approximately 0.6 before it starts increasing again and approaches 1 much later than the other two water-cuts.

As suggested by the CRTD curves, with geometry (c), MRT is the highest at a water-cut of $21 \%$. Figure 18 shows the effect of water-cut on MRT with geometry (c). MRT is the highest at $21 \%$ water-cut. It reduces to the minimum value at $32 \%$ water-cut and increases again at $57 \%$ water-cut.
Fig. 15 Geometry (b): Oil velocity vectors across the first baffle plate show oil velocity significantly reduces across the baffle plate

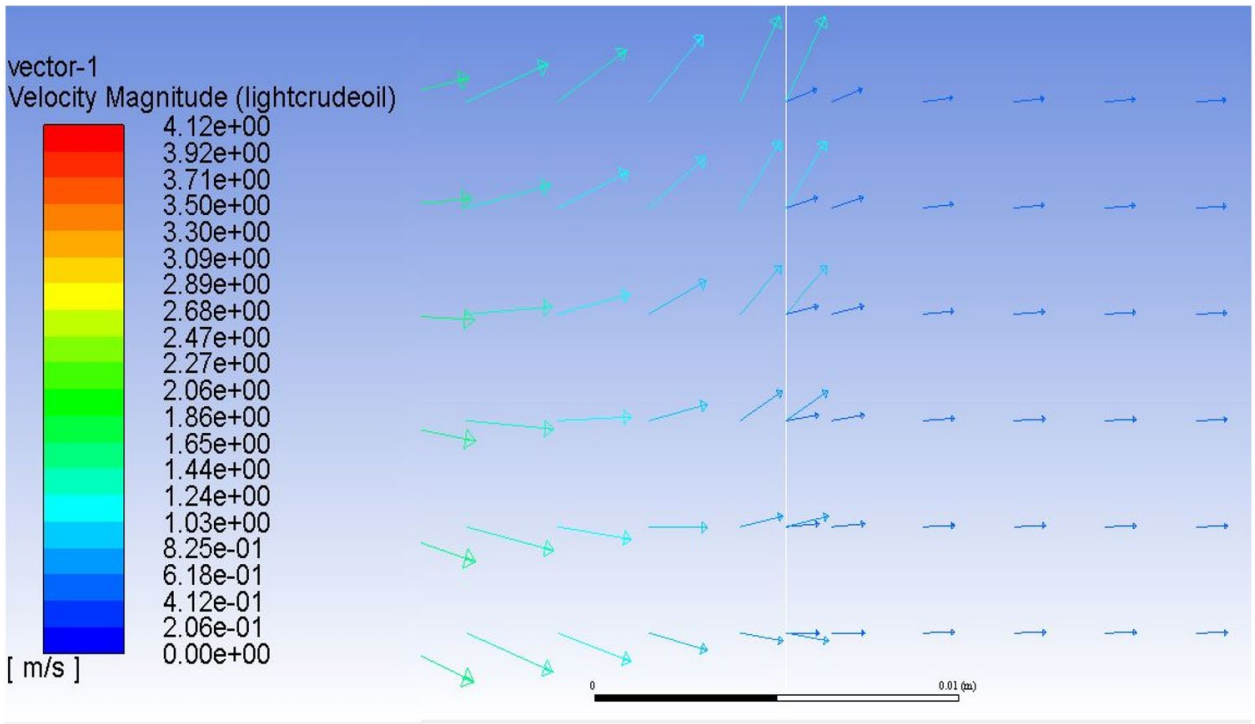

SN Applied Sciences A SPRINGER NATURE journal 
Fig. 16 Geometry (b): Oil velocity vectors across the second baffle plate show oil velocity doesn't reduce any further significantly across the second baffle plate
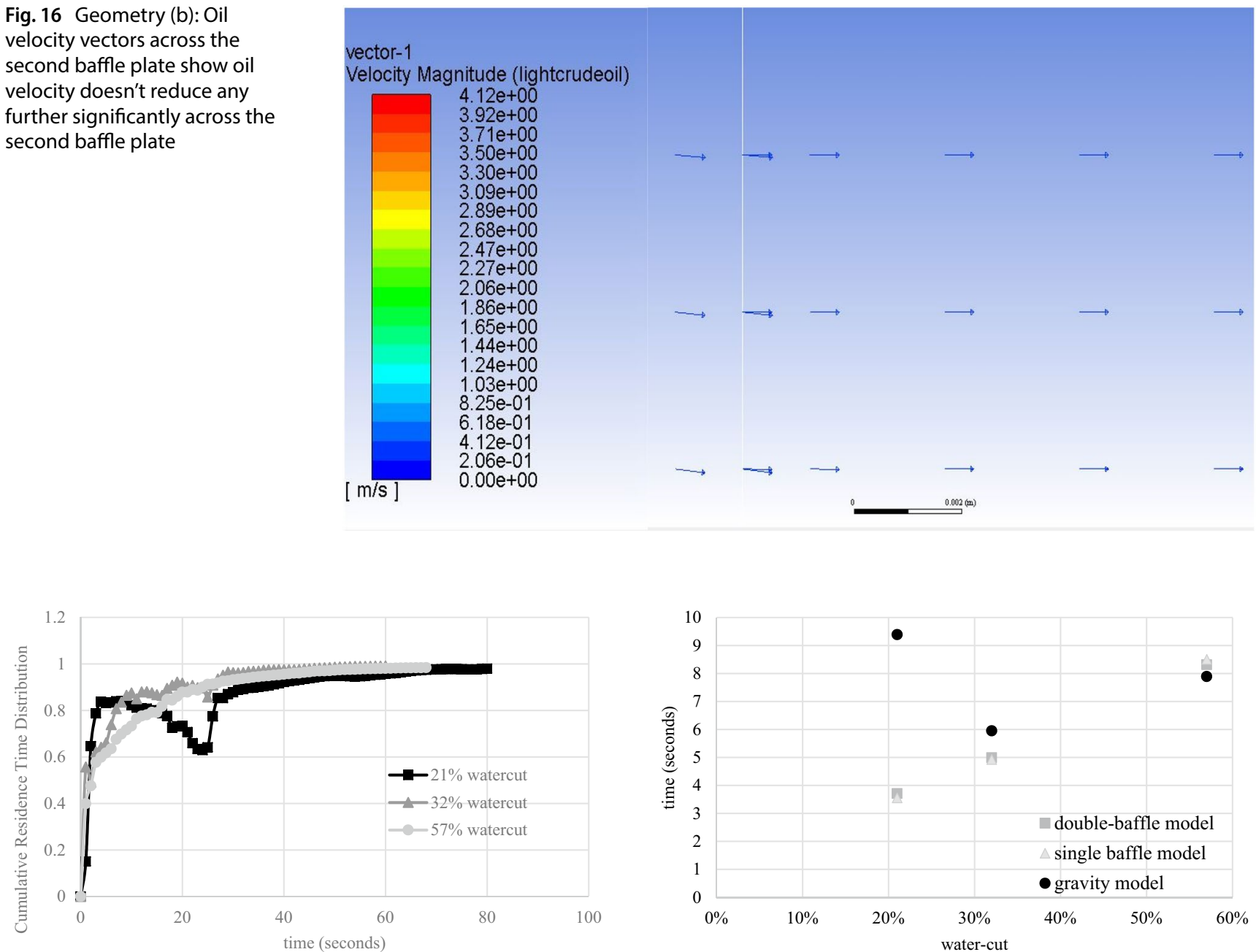

Fig. 17 Geometry (c): Cumulative Residence Time Distribution at different water-cuts

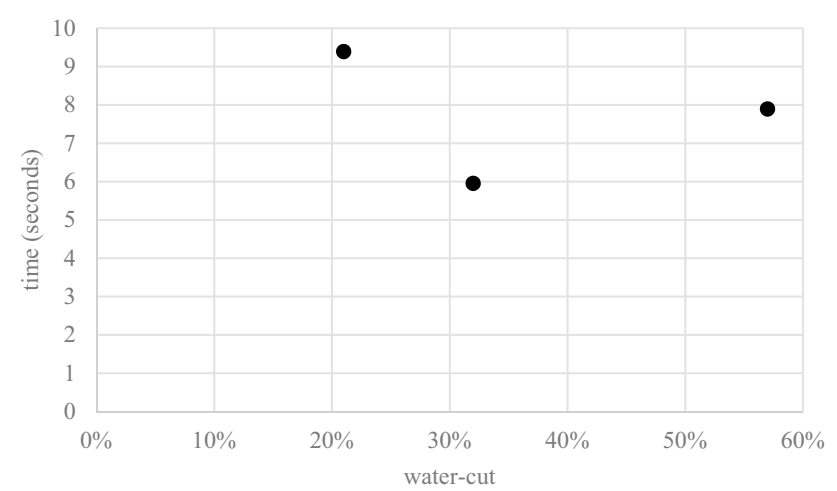

Fig. 18 Geometry (c): Effect of water-cut on hydrocarbon mean residence time (MRT)

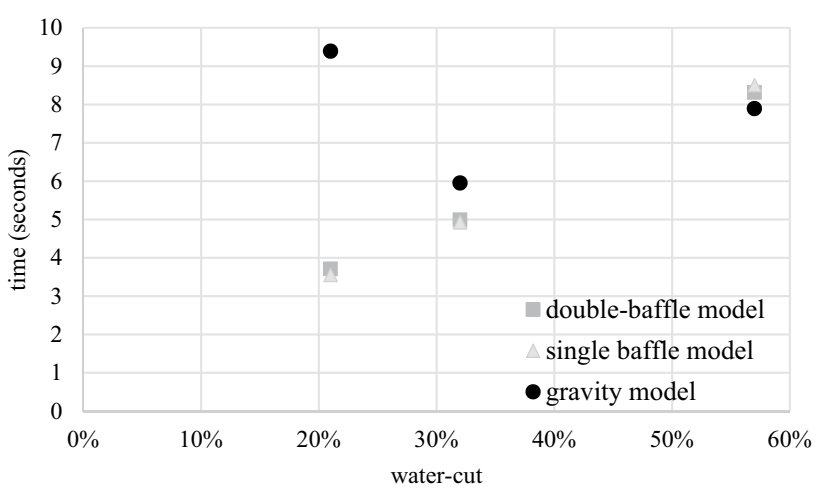

Fig. 19 Hydrocarbon mean residence time: all three separator geometries

\subsection{Comparison between the separator geometries}

At lower water-cuts of $21 \%$ and $32 \%$, geometry (c) allows larger MRTs than geomteries (a) and (b). At $57 \%$ water-cut, the MRT values are comparable between the three separator geometries. Figure 19 shows the MRT with the three separator geometries at the given water-cuts.

Currently there are very few articles that report CFD results on liquid-liquid separation in horizontal separators and none of these report mean residence time using residence time distribution. The model used by the authors is qualitatively validated against experiments and suggests its use to predict separator flow characteristics at different water-cuts. In the present article, the authors 
use the numerical model to assess the influence of certain features of the separator geometry on hydrocarbon mean residence time (MRT). CFD results suggest that MRTs improve only slightly with the second baffle plate introduced. However, the results show that much higher MRT are possible at lower water-cuts of $21 \%$ and $32 \%$ with the gravity assisted separator. Therefore, the gravity assisted horizontal separator may be more efficient at low watercuts. The authors believe the data obtained will be useful to researchers associated with experimental measurement of two-phase flow characteristics in horizontal separators.

\section{Conclusion}

Computational fluid dynamics (CFD) simulations are performed to predict cumulative residence time distributions (CRTD) and mean residence times (MRT) in three different separator configurations (geometries (a), (b), and (c)) with different water-cuts in a mixture of light crude oil and water. Geometry (a) and geometry (b) are conventional horizontal separators with a single baffle plate and two baffle plates respectively. Geometry (c) is a gravity assisted horizontal separator having the same gravity separation zone dimensions as geometries (a) and (b). In addition, the gravity assisted separator has a downward slanted throat section connecting the primary zone with the gravity separation zone. In geometries (a) and (b), MRT increases with increase in water-cut. These results show that separator performance improves with increase in water-cut for geometries (a) and (b). These results are consistent with the observations of previous researchers $[16,17]$. The CFD results show that with geometry (c), the largest MRT is obtained at $21 \%$ water-cut. It reduces to the minimum at $32 \%$ water-cut and increases again at $57 \%$ water-cut. These results show that at low water-cuts, the separator performance may be improved by introducing a throat section connecting the primary zone with the gravity separation zone in a horizontal separator. The authors suggest performing 2-phase flow experiments in horizontal separators with a throat section to confirm the results.

Funding The authors thank the research council of university (RCU) at California State University, Bakersfield for their funding (BKRSCPJ0039) for this project.

Availability of data and material Not applicable.

Code availability Not applicable.

\section{Compliance with ethical standards}

Conflict of interest The authors declare no conflicts of interests or competing interests.

Open Access This article is licensed under a Creative Commons Attribution 4.0 International License, which permits use, sharing, adaptation, distribution and reproduction in any medium or format, as long as you give appropriate credit to the original author(s) and the source, provide a link to the Creative Commons licence, and indicate if changes were made. The images or other third party material in this article are included in the article's Creative Commons licence, unless indicated otherwise in a credit line to the material. If material is not included in the article's Creative Commons licence and your intended use is not permitted by statutory regulation or exceeds the permitted use, you will need to obtain permission directly from the copyright holder. To view a copy of this licence, visit http://creativecommons. org/licenses/by/4.0/.

\section{References}

1. Evans $F$ (1974) Equipment design handbook for refineries and plants, vol 2. Gulf Publishing, Houston, Texas

2. Arnold K, Stewart M (2008) Surface production operations, 3rd edn. Elsevier, New York

3. Sivalls CR (1987) Oil and gas separation design manual. Sivalls Incorporated, Odessa

4. Watkins RN (1967) Sizing separators and accumulators. Hydrocarb Process 46(11):253-256

5. Bradley HB (ed) (1987) Petroleum engineering handbook. Society of Petroleum Engineers, Richardson, Texas

6. Walas SM (1990) Process vessels, in chemical process equipment selection and design, 713-715 Waltham. ButterworthHeinemann, Massachusetts

7. Monnery WD, Svrcek WY (1994) Successfully specify three-phase separators. Chem Eng Prog 90:29

8. Grødal EO, Realff MJ (1999) Optimal design of two-and threephase separators: a mathematical programming formulation. Paper presented at SPE annual technical conference and exhibition, Houston, Texas, USA, 3-6 October. SPE-56645-MS. https:// doi.org/https://doi.org/10.2118/56645-45-MS

9. Simmons MJH, Komonibo E, Azzopardi BJ, Dick DR (2004) Residence time distributions and flow behaviour within primary crude oil-water separators treating well-head fluids. Chem Eng Res Des 82(10):1383-1390

10. Hallanger A, Soenstaboe F, Knutsen T (1996) A simulation model for three-phase gravity separators. Paper presented at the SPE Annual Technical Conference and Exhibition, Denver, Colorado, USA, day(s) month. SPE-36644-MS. https://doi.org/https://doi. org/10.2118/36644-MS

11. Hansen E (2001) Phenomenological modeling and simulation of fluid flow and separation behavior in offshore gravity separators. ASME-Publ-PVP 431:23-30

12. Yu P, Liu S, Wang Y et al (2012) Study on internal flow field of the three-phase separator with different entrance components. Procedia Eng 31:145-149. https://doi.org/10.1016/j.proeng.2012. 01.1004

13. Kharoua N, Khezzar L, Saadawi H (2013) CFD simulation of threephase separator: effects of size distribution. ASME 2013 fluids engineering division summer meeting: V01CT17A013. 
14. Ghaffarkhah A, Shahrabi M, Moraveji M et al (2017) Application of CFD for designing conventional three phase oilfield separator. Egypt J Pet 26(2):413-420

15. Le TT, Ngo SN, Lim Y et al (2018) Three-phase Eulerian computational fluid dynamics of air-water-oil separator under off-shore separation. J Pet Sci Eng 171:731-747. https://doi.org/10.1016/j. petrol.2018.08.001

16. Simmons MJ, Wilson JA, Azzopardi BJ (2002) Interpretation of the flow characteristics of a primary oil-water separator from the residence time distribution. Chem Eng Res 80(5):471-482

17. Acharya T, Casimiro L (2020) Evaluation of flow characteristics in an onshore horizontal separator using computational fluid dynamics. J Ocean Eng Sci 5(3):261-268

18. Behin J, Aghajari M (2008) Influence of water level on oil-water separation by residence time distribution curves investigations. Sep Purif Technol 64(1):48-55

19. Zeevalkink JA, Brunsmann JJ (1983) Oil removal from water in parallel plate gravity-type separators. Water Res 17(4):365-373

20. Zemel B, Bowman RW (1978) Residence time distribution in gravity oil-water separations. J Pet Technol 30(02):275-282
21. Piao L, Kim N, Park H (2017) Effects of geometrical parameters of an oil-water separator on the oil-recovery rate. J Mech Sci Technol 31(6):2829-2837

22. Fluent, A.N.S.Y.S., 2013. Release 15.0, user manual. ANSYS, Canonsburg, PA.

23. Laleh AP, Svrcek WY, Monnery WD (2012) Design and CFD studies of multiphase separators - a review. Can J Chem Eng 90(6):1547-1561

24. Oshinowo LM, Vilagines RD (2020) Modeling of oil-water separation efficiency in three-phase separators: Effect of emulsion rheology and droplet size distribution. Chem Eng Res Des 159:278-290

25. Gharaibah E, Read A, Scheuerer G (2015) Overview of CFD multiphase flow simulation tools for subsea oil and gas system design, optimization and operation. In: OTC Brasil. Offshore technology conference.

Publisher's Note Springer Nature remains neutral with regard to jurisdictional claims in published maps and institutional affiliations. 